PAPER

\section{Thermal behavior of phenol-furfuryl alcohol resin/carbon nanotubes composites}

To cite this article: L S Conejo et al 2018 Mater. Res. Express 5045701

View the article online for updates and enhancements.

\section{Related content}

- Degradation behavior of carbon
$\frac{\text { nanotubes/phenol-furfuryl alcohol }}{\text { multifunctional composites with aerospace }}$
$\frac{\text { application }}{\text { LS Conejo, M L Costa, S S Oishi et al. }}$
- Multifunctional green nanostructured
$\underline{\text { composites: preparation and }}$
characterization
Oarissa Stieven Montagna, Silvia Sizuka
- Piezoresistivity of resin-impregnated
carbon nanotube film at high temperatures
Min Li, Tianyi Zuo, Shaokai Wang et al.

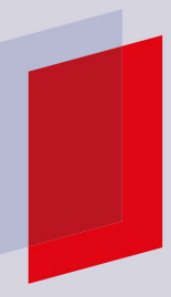

\section{IOP ebooks}

Bringing you innovative digital publishing with leading voices to create your essential collection of books in STEM research. Start exploring the collection - download the first chapter of every title for free. 


\section{Thermal behavior of phenol-furfuryl alcohol resin/carbon nanotubes composites}

RECEIVED

REVISED

16 March 2018

ACCEPTED FOR PUBLICATION

22 March 2018

PUBLISHED

11 April 2018

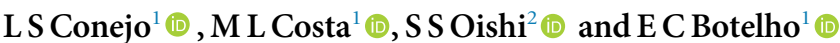 \\ 1 Department of Materials and Technology, UNESP, Guaratingueta, Brazil \\ 2 National Institute for Space Research, INPE, São José dos Campos, Brazil \\ E-mail: luizaconejo@yahoo.com.br
}

Keywords: nanocomposites, phenol-furfuryl alcohol resin, carbon nanotubes, specific heat, linear thermal expansion coefficient

\begin{abstract}
Phenol-furfuryl alcohol resins (PFA) are excellent candidates to replace existing thermoset matrices used in obtaining insulating systems or carbon materials, both in its pure form and reinforced with nanoscale structures. This work had as main purpose synthesize and investigate thermal characterization of PFA resin and its nanostructured composites with different concentrations of carbon nanotubes $(0,0.1,0.5$ and $1.0 \mathrm{wt} \%)$. The DSC analysis was performed to estimate the specific heat $\left(c_{\mathrm{p}}\right)$ of the cured samples and thermomechanical analysis to find the linear thermal expansion coefficient $(\alpha)$. From these results, the $c_{p}$ values found for the PFA system was similar to that described in the literature for the phenolic resin. The $c_{p}$ increased with the increase in the CNT concentration in the system up to $0.5 \%$. The coefficient of linear thermal expansion obtained by TMA technique for PFA sample was $33.10^{-6} /{ }^{\circ} \mathrm{C}$ which was close to the $\alpha$ value of phenolic resin $\left(40\right.$ to $\left.80.10^{-6} /{ }^{\circ} \mathrm{C}\right)$.
\end{abstract}

\section{Introduction}

Phenolic resins are produced on a large scale for years, as they have satisfactory properties for different purposes and are relatively inexpensive. One of the uses of phenolic resin is the electro-electronic industry and electrical insulation products or those applications that require high carbon content $[1,2]$.

The beginning of synthetic products for insulations started with phenol-formaldehyde resins, which were used in different electrical applications. Other synthetic products such as polyvinyl chloride, polyesters, polyethylenes, polyurethane, epoxy, etc, were introduced later [1]. Composites and nanocomposites based on thermosetting resins have been widely used in electrical insulation applications, however, nanocomposites have emerged because they improve the overall characteristics (i.e. mechanical, electrical, thermal, etc) as a result of enhanced interactions at the interfaces [1,3-5]. In addition, the greater extent of interactions can enhance the dielectric properties, which includes higher energy storage or lower dielectric loss, and improved power dissipation [4].

Nanotechnology has been very important in current research, development and innovation activities. Many nanometric fillers composed of different materials and different sizes and shapes have been used, but in particular, what gained most attention was the carbon nanotubes (CNT) discovered by Iijima [6].

Although phenolic resin has been widely used in different applications, they have somedisadvantages such as high porosity, moderate values of tension and compression and low chemical resistance after curing [2]. On the other hand, the furfuryl alcohol resin is considered a bioresin obtained from biomass rich in pentose and provide interesting characteristics such as higher hardness and good mechanical and chemical resistance [7]. However, this resin has not been commercialized on a larger scale due to the difficulty in control its polycondensation reaction [8].

To resolve this issue, the phenolic and furfuryl alcohol resins can be combined to obtain resins with improved properties and methods of synthesis and cure better controlled than the separate resins.

The 'interfaces' between inorganic fillers and the organic polymers, such as phenolic resin systems, represent the key to understand the mechanisms and phenomena that control the properties of nanocomposites used as 
advanced materials [9]. Therefore, interfacial control is critical for achieving good coupling between the inorganic filler and the base polymer. The present goal of the research studies in this field is to optimize these benefits and to provide a better understanding of the physical and chemical structure of the interface region [10].

Thus, to know the thermal properties of a nanocomposite is fundamental to understand where it can be applied, mainly in electro-electronic components. One of the properties that must be known is the specific heat and coefficient of linear thermal expansion of the material.

Specific heat is the amount of heat required for each gram of a substance to undergo a temperature change corresponding to $1^{\circ} \mathrm{C}$. This magnitude is a characteristic of each type of substance and indicates the behavior of the material when exposed to a heat source. Some factors influence specific heat, such as intermolecular forces and impurities. It is known that the greater the intermolecular bonding strength of the material, the greater the energy required for the rupture of the bonds and effective transformations of the material. Generally, materials that have hydrogen bonds in their structure have high specific heat. Impurities present in various materials may alter the specific heat value of the substance.

The major issue for determining the specific heat of a nanocomposite is to have control of the amount of heat exchanged between the different bodies when subjected to actual operating conditions. The greater the specific heat of a nanocomposite, the greater the amount of heat that must be supplied or withdrawn from it so that temperature variations occur.

In addition, it is expected that the material does not shrink or expand with use over a given temperature range. For this reason, it is important to know the coefficient of linear thermal expansion of nanocomposites that will be used in the electro-electronic industry.

So, due to limited information available in the literature about the composites PFA/CNT and to describe the scientific development of nanocomposites electrical features desired in power engineering, the present article is focused on the thermal properties of phenol-furfuryl alcohol (PFA) composites with different percentages of carbon nanotubes. Specific heat was determined by differential scanning calorimetry (DSC) and the linear thermal expansion coefficient via thermomechanical analysis (TMA).

\section{Experimental}

\subsection{Synthesis of phenol-furfuryl alcohol (PFA) resin}

The synthesis route used in this work is described in previous work [11]. Briefly, first phenol and formaldehyde (supplied by Vetec) is reacted in the presence of a sodium hydroxide (from Nuclear) for $30 \mathrm{~min}$ at $90{ }^{\circ} \mathrm{Cs}-95^{\circ} \mathrm{C}$. Then, furfuryl alcohol (supplied by Fluka) is added along with a quantity of dilute sulfuric acid (from Vetec) sufficient to neutralize the basic catalyst and then catalyze the acid condensation of furfuryl alcohol until viscosity around $1000 \mathrm{mPa}$.s. The synthesized PFA resin was neutralized with $\mathrm{NaOH}$ until $\mathrm{pH}$ around 6-7. The presence of water in the PFA resin was removed using a rotary evaporator at reduced pressure until moisture of around $5 \%$.

\subsection{Obtaining of nanostructured composites PFA/CNT}

Multiwalled carbon nanotubes (MWCNTs) used in this study were supplied by Bayer, coded as $150 \mathrm{C}$ Baytubes P. Samples of PFA containing CNT concentrations of $0.1,0.5$ and $1.0 \mathrm{wt} \%$ were prepared with the assistance of an ultrasonic probe (Sonics \& Materials, Model VC 750, $750 \mathrm{~W}, 20 \mathrm{kHz}$, for $4 \mathrm{~min}$ ). PFA samples was then catalyzed with $4 \% \mathrm{w} / \mathrm{w}$ of p-toluenesulfonic acid solution $(60 \% \mathrm{w} / \mathrm{v})$ and cured in a vacuum oven with step heating at $60,90,120,150$, and $180{ }^{\circ} \mathrm{C}$ (each for $2 \mathrm{~h}$ ).

\subsection{Differential scanning calorimetry (DSC)}

The equipment used for the analyzes was the DSC brand TA Instruments model 2940 previously calibrated with indium. Cured samples of approximately $2 \mathrm{mg}$ were used in a standard-hermetically sealed aluminum sample under constant nitrogen flow $\left(20 \mathrm{ml} \mathrm{min}^{-1}\right)$ at a heating rate of $20^{\circ} \mathrm{C} \mathrm{min}{ }^{-1}$, the temperature ranging from $25^{\circ} \mathrm{C}$ to $300^{\circ} \mathrm{C}$. The initial temperature was maintained for 4 min to establish thermal equilibrium.

The procedure adopted to determine the specific heat of the studied material consisted of 3 steps:

(1) testing of samples (three for each type), the empty pan and reference material (sapphire), by differential scanning calorimetry (DSC);

(2) subtracting the DSC curves of the samples and sapphire curve relative to baseline; and

(3) determination of $c_{p}$. All conditions used in this step follow the ASTM E1269-11 (Standard Test Method for Determining Specific Heat Capacity by Differencial Scanning Calorimetry) [12]. 


\subsection{Thermomechanical analysis (TMA)}

TMA/SS 6100 (Thermo Mechanical Analysis) SII Nanotechnology Inc. - Seiko model EXSTAR6000 was used in the present work. Analyzes were performed according to ASTM E831, to understand the behavior of the linear thermal expansion coefficient of samples cured PFA and its nanostructured composites. Following the standard, samples were heated from 25 to $300{ }^{\circ} \mathrm{C}$ at a heating rate of $3{ }^{\circ} \mathrm{C} \mathrm{min}^{-1}$ and each sample was shaped to the dimensions of $(8 \times 8 \times 3) \mathrm{mm}$.

Each sample was analyzed twice, that is, the same sample was heated and cooled, heated again, as mentioned in the standard [13]. This procedure was performed for PFA resin with different percentages of CNT $(0 ; 0.1 ; 0.5$ and $1.0 \% \mathrm{w} / \mathrm{w})$. All analyzes were performed in triplicate. To calculate the coefficient of expansion $(\alpha)$, the second run curve was used.

\section{Results and discussions}

\subsection{Specific heat $\left(c_{p}\right)$}

The physical properties of a material are related to changes in temperature and are responsible for possible suitability of a material for a particular purpose [14]. The specific heat evaluates the energy required to accomplish an increase of $1{ }^{\circ} \mathrm{C}$ on a sample of $1 \mathrm{~g}$ [15].

We can thus assume in general: 'The higher the specific heat, the lower the temperature variation as a given amount of heat is absorbed'. But specific heat does not tell us just how much heat must be absorbed by a material before its temperature varies; it also describes the material's ability to release heat to cool an object. So, the smaller the heat capacity, the greater the material's ability to release heat so that it cools.

This property can be determined by the technique of differential scanning calorimetry according to ASTM E1269-11. Specific heat being an intrinsic property of the material, for composites, it is expected that this property is influenced as the reinforcement is added to the matrix. In the case of nanostructured composite $\mathrm{PFA} / \mathrm{CNT}$, the CNT being a good thermal conductor, it is expected that its introduction decrease the specific heat of the composite as its concentration increases.

For each sample, the curve to calculate the specific heat is generated from the empty sample holder, which is then used to initially confine sapphire and after the sample. In the present work to avoid repetition, only one representative DSC curve is shown in figure 1 for the standard sapphire.

Figure 1 also shows the thermal profile of the cured PFA and with $0.1,0.5$ and $1 \mathrm{wt} \%$ of reinforcement. It is observed that the sample presents a deviation from the baseline in the temperature range studied $\left(50^{\circ} \mathrm{C}\right.$ to $300^{\circ} \mathrm{C}$ ) of approximately $0.24 \mathrm{~mW}$ for pure PFA and $0.63 \mathrm{~mW}, 0.75 \mathrm{~mW}$, and $0.50 \mathrm{~mW}$ for PFA samples with $0.1,0.5$, and $1 \mathrm{wt} \%$ of CNT, respectively. This suggests that the PFA samples suffer thermal change when given certain quantity of heat, and this variation in the case of PFA is not constant, because it increases with increasing CNT\% until the concentration of $0.5 \%$.

Based on the data of figure 1, the $c_{p}$ values were calculated in accordance with equations (1) and (2) and the results are shown in table 1 . In addition, figure 2 shows a better view of the results for different concentrations of CNT.

For the calculation of $c_{p}$, the equations (1) and (2) were used [19]:

$$
E=\left[\frac{\mathrm{b}}{60 . \mathrm{Dst}}\right] \cdot[\mathrm{Wst} . \mathrm{cp}(\mathrm{st})+\Delta \mathrm{W} \cdot \mathrm{cp}(\mathrm{c})]
$$

Where:

$\mathrm{b}=$ heating rate, $\mathrm{K} / \mathrm{min}$;

$c_{\mathrm{p}}(\mathrm{st})=$ specific heat capacity of the sapphire standard, $\mathrm{J}(\mathrm{g} . \mathrm{K})^{-1}$;

$\mathrm{c}_{\mathrm{p}}(\mathrm{c})=$ specific heat capacity of the specimen holder, $\mathrm{J}(\mathrm{g} . \mathrm{K})^{-1}$;

$\mathrm{E}=$ calorimetric sensitivity of the DSC apparatus;

Dst $=$ vertical displacement between the specimen holder and the sapphire DSC thermal curves at a given temperature, $\mathrm{mW}$;

Wst $=$ mass of sapphire, $\mathrm{mg} ;$ and

$\Delta \mathrm{W}=$ difference in mass between the empty specimen holder and the standard specimen holder, $\mathrm{mg}$ [12].

Using calorimetric sensitivity, E, calculated in equation (1), the specific heat capacity of the test specimen was calculated as follows equation (2) [12]:

$$
c p(s)=\frac{(60 . \mathrm{E} \cdot \mathrm{Ds})}{\mathrm{W} s \cdot \mathrm{b}}-\frac{\Delta \mathrm{W} \cdot \mathrm{cp}(\mathrm{c})}{\mathrm{Ws}}
$$

Where:

$c_{\mathrm{p}}(\mathrm{s})=$ specific heat capacity of the specimen, $\mathrm{J}(\mathrm{g} \cdot \mathrm{K})^{-1}$; 

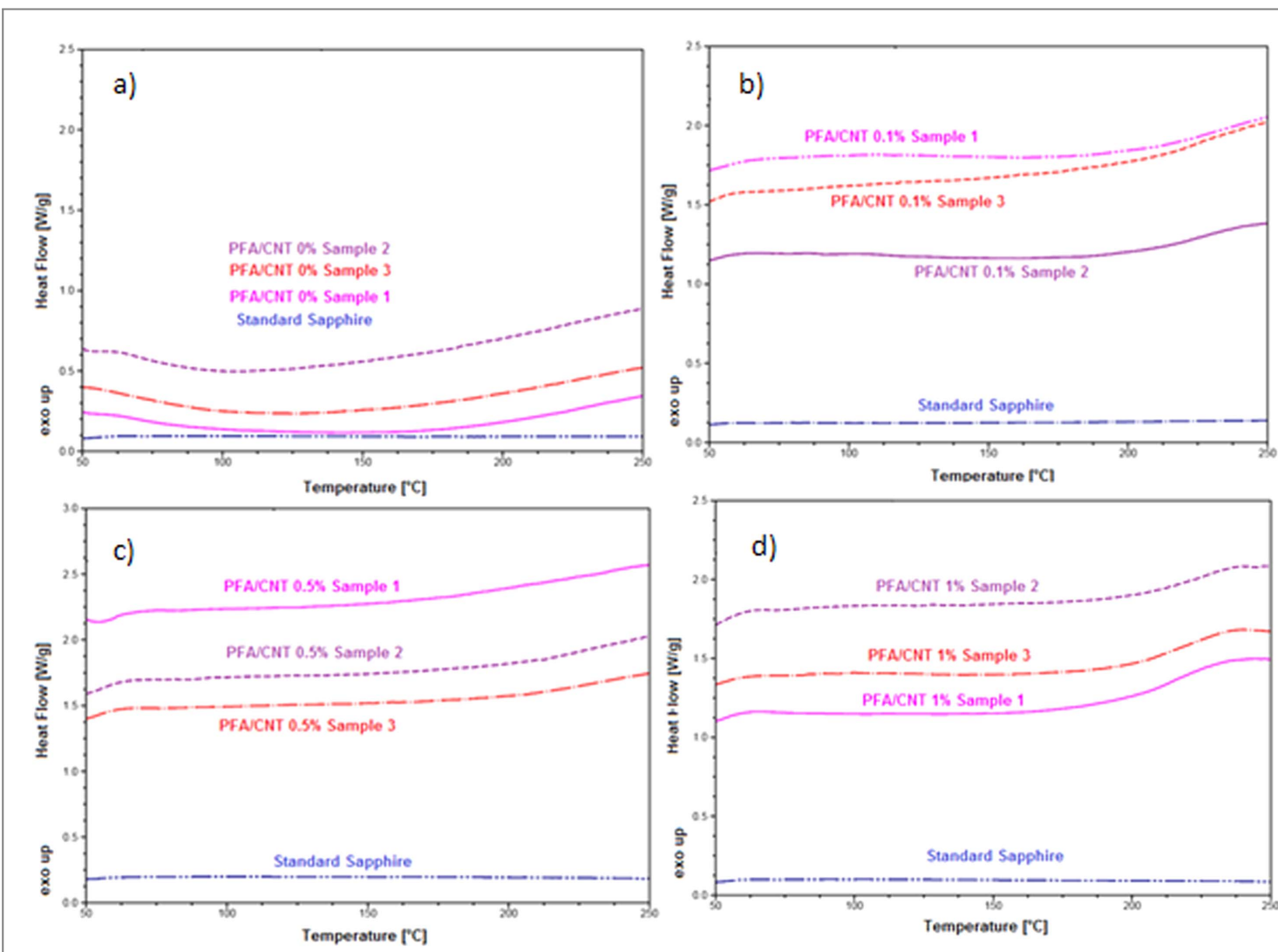

Figure 1. DSC curves of PFA/CNT samples with: (a) 0.0 , (b) 0.1 , (c) 0.5 , and (d) $1 \mathrm{wt} \%$ of reinforcement.

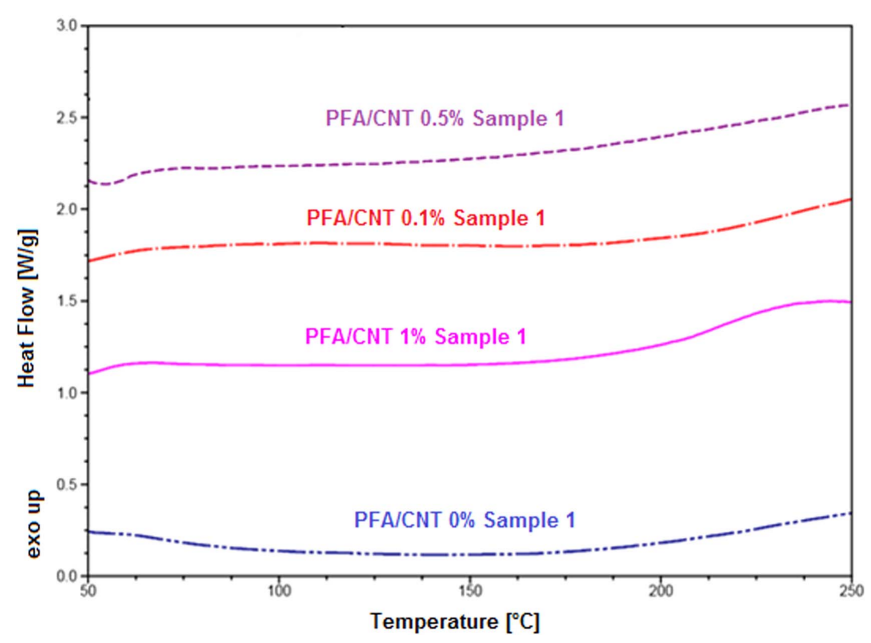

Figure 2. DSC curves of PFA/CNT samples with different $\%$ of CNT (replicate 1).

Table 1. $c_{\mathrm{p}}$ values calculated for cured PFA and its nanocomposites PFA/CNT.

Sample (PFA/CNT) $\quad c_{p}[$ J/g.K $]($ Temperature $370 \mathrm{~K})$

$\begin{array}{ll}0 \%{ }^{\mathrm{a}} & 1.91 \pm 0.18 \\ 0.1 \%^{\mathrm{a}} & 3.15 \pm 0.61 \\ 0.5 \%^{\mathrm{a}} & 3.66 \pm 0.40 \\ 1.0 \%^{\mathrm{a}} & 2.11 \pm 0.26\end{array}$

${ }^{\mathrm{a}}$ performed in triplicate. 


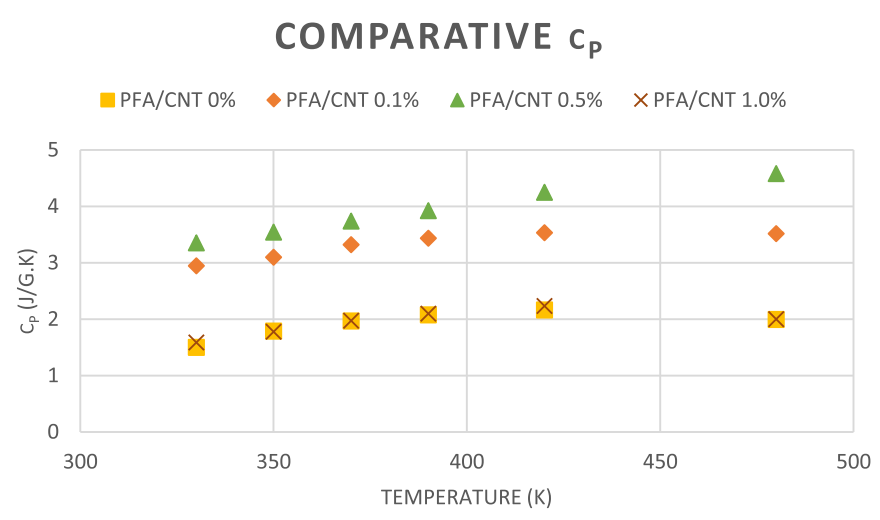

Figure 3. Comparative chart of the $c_{p}$ variation between samples.

Ds $=$ vertical displacement between the specimen holder and the specimen DSC thermal curves at a given temperature, $\mathrm{mW}$;

$\Delta \mathrm{W}=$ difference in mass between the empty specimen holder and the test specimen holder if the same holder is not used for both runs (In the case of this experiment is used the same sample holder for both runs).

Other symbols are defined in equation (1) [12].

According to the data available in the literature [16] the $c_{\mathrm{p}}$ of phenolic resin is $1.92 \mathrm{~J} \mathrm{~g}^{-1} \cdot \mathrm{K}$ at $370 \mathrm{~K}$ $\left(96.85^{\circ} \mathrm{C}\right.$ ), and as can be seen in table 1 , the value of $\mathrm{c}_{\mathrm{p}}$ found for the PFA (approximately $1.91 \mathrm{~J} \mathrm{~g}^{-1} . \mathrm{K}$ ) is close to the value of the phenolic.

$c_{p}$ value tends to increase with increasing concentration of CNT until $0.5 \%$, above this concentration the $c_{p}$ value decreases. An increase of $65 \%$ in the cp value can be observed when only $0.1 \% \mathrm{CNT}$ is added to the composite. That is, the introduction of CNTs into the composites increases the $c_{p}$ value, and the higher the composite specific heat, the greater the amount of heat that must be supplied or withdrawn for temperature variations. Thus, because the thermal conductivity is inversely proportional to the $c_{p}$, according to equation (3), [17] (ASTM E 1952-11 Standard Test Method for Conductivity and Thermal Diffusivity by Modulated Temperature Differential Scanning Calorimetry) it is verified that the introduction of CNT makes the composite a better thermal insulation than the polymer matrix itself.

$$
\lambda_{0}=\frac{\left(8 L C^{2}\right)}{\left(c_{p} \cdot m \cdot d^{2} \cdot P\right)}
$$

Where:

$\lambda_{0}=$ thermal conductivity $(\mathrm{W} /(\mathrm{K} . \mathrm{m}))$;

$\mathrm{L}=$ sample thickness $(\mathrm{mm})$;

$\mathrm{C}=$ thermal capacity $(\mathrm{mJ} / \mathrm{K})$;

$c_{\mathrm{p}}=$ specific heat $(\mathrm{J} /(\mathrm{g} \cdot \mathrm{K}))$;

$\mathrm{m}=$ sample mass $(\mathrm{mg})$;

$\mathrm{d}=$ sample diameter $(\mathrm{mm})$; and

$\mathrm{P}=$ time course (s) [24].

In figure 3 the comparative chart of $c_{\mathrm{p}}$ variations as a function of temperature in the samples of PFA/CNT is presented in different concentrations of carbon nanotubes. It is observed that the samples have similar profiles in terms of $c_{p}$, and the increase in the $c_{p}$ value is checked with increasing the temperature until approximately $150{ }^{\circ} \mathrm{C}$. After this temperature the $\mathrm{c}_{\mathrm{p}}$ tends to a slight decrease or presents the tendency to stabilize to a constant value. It is worth mentioning that the highest $c_{\mathrm{p}}$ value is obtained with the addition of $0.5 \% \mathrm{CNT}$ followed by the $0.1 \% \mathrm{CNT}$ concentration. The value of $\mathrm{c}_{\mathrm{p}}$ found for sample with $1.0 \% \mathrm{CNT}$ was the same for sample without CNT. This suggests that samples produced with CNT concentration higher than $0.5 \%$ does not present the same homogeneous dispersion in the polymer matrix, thus losing its function in the thermal property. This fact CNT dispersion for different concentrations behave differently for each material is described by the literature [18, 19].

It is known that $c_{p}$ varies with temperature. According to the quantum theory of thermodynamics, $c_{p}$ tends to increase with increasing temperature until it reaches a certain temperature known as the Debye temperature, where $c_{p}$ becomes relatively constant. Thus these values of $c_{p}$ are very close to each other because probably $150{ }^{\circ} \mathrm{C}$ is the temperature considered as the Debye temperature for the studied materials and, therefore, the values for $\mathrm{c}_{\mathrm{p}}$ should be approximately equal, or according to the classical theory and the Law of Dulong and Petit equal to $3 \mathrm{R}\left[(3)\left(8,31 \mathrm{~J} \mathrm{~mol}^{-1}-\mathrm{K}\right)=24.9 \mathrm{~J} \mathrm{~mol}^{-1}-\mathrm{K}\right][20-22]$. The thermal conductivity is inversely proportional 
to the specific heat. Metals are the best heat conductors, i.e., have higher thermal conductivity values (lower $\left.c_{p}\right)$ and polymers are the best insulators (higher $\mathrm{c}_{\mathrm{p}}$ ).

\subsection{Coefficient of linear thermal expansion $(\alpha)$}

Within a limited linear range of temperature, one may consider that there is a linear relationship between thermal deformation $\left(\varepsilon_{\mathrm{T}}\right)$ expansion $(+)$ or contraction $(-)$ suffered by a material and the change in temperature $(\Delta \mathrm{T})$ imposed to it. It should be noted that the normal component of strain is dimensionless and represents the ratio of a length variation relative to the initial length of it. The linear relationship of these two quantities being $\left(\varepsilon_{\mathrm{T}} / \Delta \mathrm{T}\right)$, is defined by a coefficient of linear thermal expansion $(\alpha)$ of the material [17].

Typically for $\Delta \mathrm{T}>0$ the material expands and $\Delta \mathrm{T}<0$ is a contraction, since in most cases $\alpha$ is positive. Materials that exhibit this negative variation can mention the non-isotropic aramid fibers $\left(-2.33 .10^{-6} /{ }^{\circ} \mathrm{C}\right.$ (longitudinal) and $41.10^{-6} /{ }^{\circ} \mathrm{C}$ (transverse) ) and carbon, in which $\alpha$ is negative in the longitudinal direction and positive in the transverse position of the filament. The thermoset matrices used in polymer composites exhibit positive thermal expansion coefficients and reasonably high [23].

The ASTM E831 suggests that the samples should be between 2 and $10 \mathrm{~mm}$ in length and width, and thickness can not be larger than $10 \mathrm{~mm}$. Initially the sample must be measured with an instrument with a maximum error of $\pm 25 \mu \mathrm{m}$ to a temperature between 20 and $25^{\circ} \mathrm{C}$ [12].

The equipment must be calibrated and reset to zero when the tip stays in height zero. The sample shall be placed under the tip and centralized. It should be selected a force compatible with the sample material between 1 and $10 \mathrm{mN}$. The heating rate chosen should be a maximum of $5^{\circ} \mathrm{C} \mathrm{min}^{-1}$, the lower the better feedback. After completion of the first analysis, a new race with the same sample tested should be performed, and so, the $\alpha$ can be calculated with greater confidence and accuracy [12].

For the calculation of $\alpha$ are used the equations (4) and (5) [12]:

$$
\begin{gathered}
\alpha_{\mathrm{m}}=\frac{\Delta \mathrm{Lsp} \times k}{\mathrm{~L} \times \Delta \mathrm{T}} \\
k=\frac{\alpha \text { ref } \times \mathrm{L} \mathrm{ref} \times \Delta \mathrm{T} \mathrm{ref}}{\Delta L \text { ref }}
\end{gathered}
$$

Where:

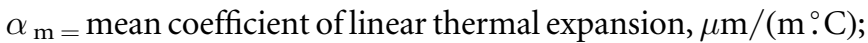

$\alpha_{\text {ref }}=$ mean coefficient of linear thermal expansion, for reference material, $\mu \mathrm{m} /(\mathrm{m} . \mathrm{C})$;

$k=$ calibration coefficient, from Test Method E 2113;

$\mathrm{L}=$ specimen length at room temperature, $\mathrm{m}$,

$\Delta \mathrm{L}_{\text {ref }}=$ change of reference material length due to heating, $\mu \mathrm{m}$;

$\mathrm{L}_{\mathrm{ref}}=$ reference material length at room temperature, $\mathrm{m}$;

$\Delta \mathrm{L}_{\mathrm{sp}}=$ change of specimen length, $\mu \mathrm{m}$;

$\Delta \mathrm{T}_{\text {ref }}=$ temperature difference over which the change in reference material length is measured, ${ }^{\circ} \mathrm{C}$;

$\Delta \mathrm{T}=$ temperature difference over which the change in specimen length is measured, ${ }^{\circ} \mathrm{C}$;

$\mathrm{T}=$ midpoint temperature of the temperature range $\Delta \mathrm{T}$.

Figure 4 shows the comparison between the curves of different concentrations of carbon nanotubes for better visualization of the results obtained.

From these results, the thermal profile determined by the TMA technique for the PFA and their nanostructured composites are similar, i.e., with increasing temperature, there is a slight expansion of the material, but it was not possible to achieve a glass transition temperature of the material in the temperature range evaluated.

Table 2 shows the values of $\alpha$ for the material found in the present work in two temperature ranges, the first between 70 and $130{ }^{\circ} \mathrm{C}$ and the second between 150 and $200{ }^{\circ} \mathrm{C}$ for all samples.

From this study the $\alpha$ ranged between $30.10^{-6} /{ }^{\circ} \mathrm{C}$ and $43.10^{-6} /{ }^{\circ} \mathrm{C}$. If we consider the standard deviation, it can be observed that the introduction of CNT practically does not affect the values of linear thermal expansion coefficient. The value found for the $\alpha$ PFA resin is within the range described in the literature for the thermoset resin systems used in polymer composites, such as epoxy resin (varying from 15 to $100.10^{-6} /{ }^{\circ} \mathrm{C}$ ) and the phenolic resin (40 to $\left.80.10^{-6} /{ }^{\circ} \mathrm{C}\right)$ [24].

The coefficient of linear thermal expansion consists of the fractional change of volume or linear dimension by temperature degree. Thus, from an atomic perspective, alpha expresses the average distance between atoms, the thermal expansion being an increase in the amplitude of vibration of the atoms leading to an expansion of the crystalline lattice. As this property is related to the structure and chemical bonds we can say that since we have an all the cases of the PFA matrix with carbon nanotubes, it is expected that the alpha values do not vary much.

Some polymeric materials undergo very large thermal expansions upon being heated, as is apparent from their linear coefficients of thermal expansion, ranging from about $50.10^{-6} /{ }^{\circ} \mathrm{C}$ and $400.10^{-6} /{ }^{\circ} \mathrm{C}$. The highest $\alpha$ 


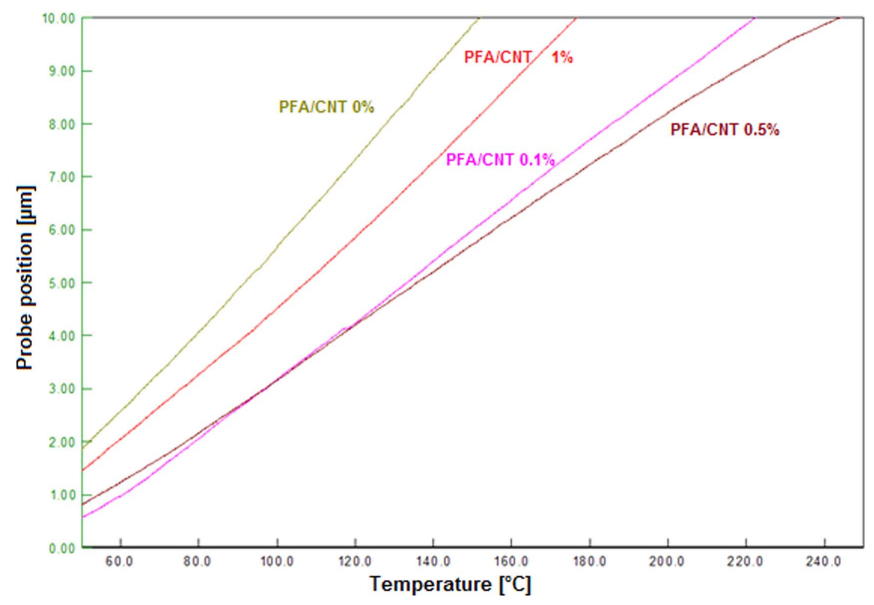

Figure 4. TMA curve of comparative of the sample PFA/CNT.

Table 2. Average values of $\alpha$ for PFA resin with different percentages of CNT.

\begin{tabular}{lcc}
\hline Material & Average value $\alpha\left(70{ }^{\circ} \mathrm{C}-130{ }^{\circ} \mathrm{C}\right)\left(10^{-6} /{ }^{\circ} \mathrm{C}\right)$ & Average value $\alpha\left(150{ }^{\circ} \mathrm{C}-200{ }^{\circ} \mathrm{C}\right)\left(10^{-6} /{ }^{\circ} \mathrm{C}\right)$ \\
\hline PFA/CNT 0.0\% & $43.15 \pm 12.98$ & $29.89 \pm 8.73$ \\
PFA/CNT 0.1\% & $36.76 \pm 3.54$ & $39.53 \pm 7.65$ \\
PFA/CNT 0.5\% & $35.42 \pm 5.10$ & $38.06 \pm 8.49$ \\
PFA/CNT 1.0\% & $41.15 \pm 1.98$ & $42.02 \pm 3.17$
\end{tabular}

values are found for linear and branched polymers, since the secondary intermolecular bonds are weak, in addition to having a minimal amount of crosslinking. As the amount of crosslinking increases, the magnitude of the expansion coefficient decreases; the lower coefficients are found for thermosetting network polymers, such as phenol formaldehyde, where the bonds are almost entirely covalent.

Therefore, it can be observed that the alpha values for the studied materials practically do not vary, even for different ranges of temperature.

\section{Conclusion}

With the use of DSC it was possible to determine the $c_{p}$ of PFA sample and their PFA/CNT nanostructured composites. The $c_{p}$ value of PFA sample is like the phenolic resin. Furthermore, it was found that $c_{p}$ increases with the introduction of the CNT in the PFA system until the concentration of $0.5 \%$. Above this (1.0\%), no change was observed in $c_{p}$ value.

The coefficient of linear thermal expansion obtained by TMA technique for PFA/CNT nanocomposites was 38. $10^{-6} /{ }^{\circ} \mathrm{C}\left( \pm 3.17 .10^{-6}\right)$, which is close to the $\alpha$ value of phenolic resin $\left(40\right.$ to $\left.80.10^{-6} /{ }^{\circ} \mathrm{C}\right)$. In addition, the introduction of the CNT in PFA systems did not affect the $\alpha$ values, so the amount of CNT depends on the intended application and not by the dependence of the $\alpha$ values.

\section{Acknowledgments}

The authors acknowledge the financial support received, respectively, from FAPESP (Fundação de Amparo à Pesquisa do Estado de São Paulo, Brasil) under grants 2012/24668-8.

\section{ORCID iDs}

L S Conejo (1) https://orcid.org/0000-0001-5533-1374

M L Costa (i) https://orcid.org/0000-0001-9492-8544

S S Oishi (iD https:// orcid.org/0000-0001-5540-3382

EC Botelho (10) https://orcid.org/0000-0001-8338-4879 


\section{References}

[1] Pleşa I et al 2016 Properties of polymer composites used in high-voltage applications Polymers 8173

[2] Reghunadhan Nair C P 2004 Advances in addition-cure phenolic resins Prog. Polym. Sci. 29 401-98

[3] Lau K Y, Vaughan A S and Chen G 2015 Nanodielectrics: opportunities and challenges IEEE Electr. Insul. Mag. 31 $45-54$

[4] Tomer V, Polizos G, Randall C A and Manias E 2011 Polyethylene nanocomposite dielectrics: implications of nanofiller orientation on high field properties and energy storage J. Appl. Phys. 109074113

[5] Paramane A S and Kumar K S 2016 A review on nanocomposite based electrical insulations Trans. Electr. Electron. Mater. 17 239-51

[6] Fiedler B, Gojny F H, Wichmann M H G, Nolte M C M and Schulte K 2006 Fundamental aspects of nano-reinforced composites Compos. Sci. Technol. 663115-25

[7] Domínguez J C, Grivel J C and Madsen B 2012 Study on the non-isothermal curing kinetics of a polyfurfuryl alcohol bioresin by DSC using different amounts of catalyst Thermochimica Acta 529 29-35

[8] Lebach H H 1949 Furfuryl alcohol-phenol aldehyde resinous products and method of making the same United States Patent Office 2.471 .631

[9] Oriakhi C O 2000 Polymer nanocomposition approach to advanced materials J. Chem. Educ. $771138-46$

[10] Fiedler B et al 2006 Fundamental aspects of nano-reinforced composites Compos. Sci. Technol. 66 3115-25

[11] Conejo L S et al 2017 Mater. Res. Express 4105701

[12] ASTM-E1269 2011 Standard Test Method for Determining Specific Heat Capacity by Differential Scanning Calorimetry (West Conshohocken, PA: ASTM International) (https://doi.org/10.1520/E1269-11)

[13] ASTM-E831 2012 Standard Test Method for Linear Thermal Expansion of Solid Materials by Thermomechanical Analysis (West Conshohocken, PA: ASTM International) (https://doi.org/10.1520/E0831-12)

[14] Santos W N et al 2004 Hot wire technique in the determination of thermal properties of polymers Polymer 14 354-9

[15] Resnick R, Halliday D E and Walker J 2007 Fundamentals of Physics vol 2 (New Jersey: Wiley)

[16] Wang R M, Zheng S R and Zheng Y P 2011 Polymer Matrix Composites and Technology (USA: Woodhead Published)

[17] ASTM E1952 2017 Standard Test Method for Thermal Conductivity and Thermal Diffusivity by Modulated Temperature Differential Scanning Calorimetry (West Conshohocken, PA: ASTM International) (https://doi.org/10.1520/E1952-17)

[18] Santos L F P et al 2017 Mater. Res. Express 4115037

[19] Untem F O et al 2014 Benzoxazine resin/carbon nanotube nanostructured composite's degradation kinetic J. Nanosci. Nanotechnol. 14 5145-50

[20] Çengel Y A and Boles M A 1989 Thermodynamics: An Engineering Approach 5th edn2006 (New York: McGraw-Hill)

[21] Goswami M and Sumpter B G 2009 Effect of polymer-filler interaction strengths on the thermodynamic and dynamic properties of polymer nanocomposites The Journal of Chemical Physics 130134910

[22] Higaki Y, Otsuka H and Takahara A 2006 A thermodynamic polymer cross-linking system based on radically exchangeable covalent bonds Macromolecules $392121-5$

[23] Neto F L and Pardini L C 2006 Compósitos Estruturais: Ciência e Tecnologia 1 edn (São Paulo: Edgard Blüche)

[24] Oliveira A C M 2011 Avaliação dos parâmetros de processo de reticulação do polietileno de baixa densidade MSc Thesis (Universidade Estadual Paulista ) 